\title{
Attitudes Toward Counselors and Counseling Processes: A Comparison of Chinese and American Graduate Students
}

\author{
Wei-Cheng Mau and David A. Jepsen
}

\begin{abstract}
Graduate students socialized in separate cultural settings, Taiwan and the United States, but studying at the same large university were surveyed about their (a) preferences for counselor's characteristics, (b) images of a counselor, and (c) attitudes toward counseling and coun-seling services. Results show that Chinese and American students have different preferences for and images of a counselor. Although both groups have positive attitudes toward seeking counseling, they know very little about the counseling resources and locations available. The groups also differ in their expectations of the counseling process. Some sex differ-ences were indicated, but no clear pattern emerged.
\end{abstract}

Counseling is increasingly becoming a cross-cultural activity as modern societies become more conscious of their pluralistic composition, and as increasing numbers of professional counselors are being asked to work effectively in settings that involve cultural and ethnic pluralism (Dillard, 1983). Every cultural group has its characteristic way of addressing personal issues. In helping relationships, it is imperative that counselors recognize, understand, and accept cultural differ-ences in coping patterns. For example, Vontress (1970) urged counselors to learn about cultural differences in lifestyles, val-ues, and attitudes in order to be effective in counseling indi-viduals from different cultural backgrounds.

Cross-cultural studies of attitudes toward the helping profes-sions have given considerable attention to contrasts among the varying cultural groups during the past decade. For example, several studies (Tan, 1967; Yuen \& Tinsley, 1981) have found that college students from different cultural groups differed in their expectations of a counselor's behavior. Some studies (At-kinson, Ponterotto, \& Sanchez, 1984; Dadfar \& Friedlander, 1982; Fischer \& Cohen, 1972) have identified differential attitudes to-ward psychological help. Cross-cultural differences in regard to preferences for counselor characteristics are also well docu-mented (e.g., Harrison, 1975; Proctor \& Rosen, 1981; Sattler, 1977; Bernstein, Wade, \& Hofmann, 1987).

The need for professional counseling assistance in American universities is often greater among foreign students than Amer-ican students (Dillard \& Chisolm, 1983). This is particularly true for students from oriental cultures (Alexander, Workneh, Klein, \& Miller, 1976). According to the annual census (Institute of International Education, 1986), there were 343,777 foreign students in the United States in the academic year of 1985-1986. Of all foreign students surveyed, South and East Asian students composed almost half (45.6\%) of the total foreign students in the United States. The most highly represented group was Chinese (14.1\%), which included students from Taiwan (6.9\%), Hong Kong (3.1\%), and China (4.1 \%). Many of them remained in the United States after finishing their educational programs (Ho, 1973). There is an indication that the number of Chinese stu-dents will increase in the coming decades. If counselors are to serve Chinese students successfully, they need to understand Chinese students' help-seeking behaviors and attitudes and how they differ from those of American students.

In a recent review of literature, Leong (1986) concluded that when Asian Americans (a term that most often refers to Amer-ican-born Chinese and Japanese) seek counseling, they tend to (a) have a lower tolerance of ambiguity, (b) prefer a structured situation, (c) prefer problem-solving over insight-oriented psy-chotherapy, and (d) exhibit a lower level of verbal and emotional expressiveness. There is evidence of considerable overlap be-tween Asians and Asian-Americans in the conception of mental health and attitudes toward counseling (Lum, 1982; Sue, Wag-ner, Ja, Margullis, \& Lew, 1976). We speculated that native-born Chinese students should hold perceptions and attitudes similar to Asian-American students and different from American stu-dents.

The purpose of this study is to describe and compare native-born Chinese and American graduate students' preferences for counselor characteristics and their attitudes toward counseling and counseling services. Manese, Sedlacek, and Leong (1988), in their study of international students' needs, have suggested the importance of investigating subgroup differences. For ex-ample, they found differences in the perceptions and needs of male and female international students (primarily from South--east Asia). Some studies (Lee, Abd-Ella, \& Burke, 1981) on sex differences among international students, however, have yield-ed mixed results. Therefore, sex differences both within and between the two national groups will also be examined. 


\section{METHOD}

Sample

Native-born Chinese and American graduate students who were attending the University of lowa in 1986 were selected to par-ticipate in this study. The majority of Chinese students at the University of lowa were from Taiwan (327), and most of them (200) were in one of four graduate programs: engineering, math-ematical science (statistics, mathematics, and computer science), business, or education. All Taiwanese graduate students majoring in one of these fields of study were invited to participate in this study. From a list of American graduate students ma-joring in these four fields of study (approximately 1,050), every third one was invited to participate (350).

The Chinese and American graduate students were mailed a questionnaire with a letter of introduction. One follow-up letter was sent to all students who did not respond within 2-3 weeks. The sample group who returned completed questionnaires in-cluded 148 American and 102 Chinese students. The response rate was $42 \%$ of the American students and $57 \%$ of the Chinese students for an overall response rate of $50 \%$. Of the Americans, 80 were men and 68 were women. Of the Chinese, 62 were men and 40 were women. Most of the respondents (82\%) were between 22 and 32 years of age $(M=28.99, S D=4.75)$. Years of graduate study ranged from 1 to $11(M=2.69, S D=1.92)$.

The differences between the two national groups in distribution by sex marital status, and major were analyzed using the chi-square. None of the comparisons showed a difference significant at the 0.05 level: for sex, $x^{2}(1, N=250)=$ $.673, p<.412$; for marital status, $x^{2}(1, N=250)=.572, p<.449$; and for major, $x^{2}(1, N=250)=.369, p<.946$. Differences between the two national groups in age and years of graduate study were analyzed using the t-test. No significant differences were found for age, $\mathrm{t}(250)=1.12, \mathrm{p}<.262$, or years of graduate study, $\mathrm{t}(250)<1.89,<.060$. On were the basis comparable of these in terms results, it is assumed that both groups were comparable in terms of sex, marital status, age, majors, and years of graduate study.

\section{Instrument}

All students were asked to complete a four-page questionnaire.

The questionnaire was developed by the first author after reviewing the instruments used in previous research. The preliminary version, written entirely in English, was pretested on 25 Chinese and 25 American graduate students. As a result the preliminary study, the questionnaire instructions were modified for clarity and items were added for comprehensive coverage. Five Chinese students were asked if the instructions were clear and the vocabulary understandable. Whenever a judge reported a term was not clearly understood, the questionnaire was modified to include the Chinese translation in parentheses following the English word. The purpose of inserting the Chinese translations rather than distributing Chinese questionnaires to Chinese students and English questionnaires to American students was to prevent the form effect.

The questionnaire was divided into two parts, Help-Seeking Perceptions and Attitudes Toward Counseling and Processes. Only the second part will be reported here. The second part contained three sections: (a) preferences for counselor charac-teristics, (b) images of counselors, and (c) attitudes toward counseling.

The first section, preference for counselor characteristics, consisted of seven characteristics derived from Smith's (1974) Student Preference Questionnaire. Students were instructed to rank from 1 to 7 in descending order of importance the counselor characteristics of greatest concern to them when seeking help for a personal-social problem (e.g., "the counselor should be older than I"). In the second section, images of counselors, the items were derived from Tan (1967). Students were asked to circle two out of six counselor images with which they agreed. The images listed were: (a) mother, (b) father, (c) friend, (d) expert, (e) moral judge, and (f) listener. Finally, the nine items composing the last section, attitudes toward counseling, were derived from separate studies including Benedict, Apsler, and Morrision (1977), Cook, Park, Williams, Webb, Nicholson, Schneider, and Bassman (1984); and Snyder, Hill, and Derksen (1972). Students were asked to indicate on a 4-point scale the degree to which they agreed or disagreed with each of 9 statements about counseling (e.g., "I like the counselor to make decisions for me").

No reliability estimates for the scores obtained from the questionnaire were available before conducting the study. A copy of the questionnaire is available from the author upon request.

\section{Analysis}

Students' preferences for counselor characteristics were analyzed using a two-way (nationality by sex) univariate analysis of variance. Significant univariate differences were further examined using two-tailed t-tests with significance set at $p<.05$. Nationality and sex differences in the frequencies of selecting the images of counselors were analyzed using a chi-square with Yates's correction. 
Students' responses to attitudes toward counseling items were first factor analyzed to simplify interpretations. Principal-axis factor extraction and oblique rotation resulted in three relatively independent factors. These factors can be described as (a) open-ness to counseling (items numbered 1, 2, 6, and 8 in Table 1), (b) expectations of the counseling process (items numbered 3, 4, 5, and 7), and (c) obstacles to seeking counseling (item 9). A MANOV A was then performed on each of the three factors, followed by an ANOVA on each of the survey items. If significance at .05 level was found on the univariate analysis of variance, a two-tailed t-test was performed to examine the direction of differences.

\section{RESULTS}

Preferred Characteristics of a Counselor

A two-way (nationality by sex) univariate analysis of variance yielded significant differences by nationality on preference for five counselor characteristics. They were (a) "older," $F(2,246)=13.36, p<.001$, (b) "same sex," $F(2,246)$ $=5.21, p<.006$, (c) "same racal background," $F(2,246)=11.51, p<.001$, (d) "same religious background," $F(2,246)=10.40$, $p<.001$, (e) "same socioeconomic background," $F(2,246)=5.89, p<.003$. The follow up t-tests indicated the following direction of nationality differences: Chinese students on the average were more concerned than American students about counselors' age, $\mathrm{t}(249)=.85, p<.001$, and racial background, $\mathrm{t}(249)=4.64, p<.001$, whereas American students on the average were more concerned than Chinese students about counselors' religious beliefs, $1(249)=-4.35, p<.001$ and socioeconomic background, $1(249)=-3.35, p<.001$. Follow-up analysis for sex differences indicated that male students were more concerned than female students about counselors' age, $t(248)=-2.23, p<.027$, and that female students were moreconcerned than male studentsabout counselors' sex, $1(248)=2.88, p<.005$. No significant interaction was found.

The counselor characteristics of most concern to Chinese students were (a) "older than I am" (M=2.79, SD=1.67), (b)

"someone with whom I am familiar" ( $M=3.44, S D=2.20)$, and (c) "same racial background as I" $(M=3.71, S D=1.79)$. For American students, the counselor characteristics of most concern in descending order were (a) "someone with whom I am familiar" ( $M=2.96, S D=2.17)$, (b) "has similar religious beliefs as I" ( $M=3.55, S D=1.58)$, and (c) "older than I am" ( $M=3.90$, $S D=1.90)$. These rankings are based on average ranks, the variation of each rank should be taken into consideration when interpreting the magnitude of differences between rankings.

\section{Images of a Counselor}

Differences between the two nationality groups in the image of a counselor were indicated by significant chisquares: mother, $x^{2}(1, N=250)=11.38, p<.001$; friend, $x^{2}(1, N=250)=12.36, p<.001$; and listener, $x^{2}(1, N=250)=49.94$, $p<.001$. More Chinese students than American students perceived the counselor's role as one of a mother and friend. On the other hand, more American students than Chinese students perceived the counselor's role as one of a listener. No interaction was found between nationality and sex.

The three primary roles of a counselor as perceived by Chinese students in order of importance were (a) friend (75.0\%), (b) expert (61.8\%), and (c) listener (31.4\%). On the other hand, the top three roles of a counselor as perceived by American students were (a) listener (77.0\%), (b) friend (52.7\%), and (c) expert $(50.7 \%)$.

\section{TABLE 1}

\section{Comparison of American and Chinese Students' Attitudes Toward Counseling and Services}

\section{Statements about counseling}

1. Counselor could be very helpful for people with a variety of problems.

2. I would be willing to see a counselor if my problems were serious.

3. When I seek counseling, I prefer a direct, concrete answer to my concern.

4. I like the counselor to make decisions for me.

5. When I seek counseling, I prefer one-to-one counseling rather than group counseling.

6. When tests are utilized by a counselor, they are usually helpful.

7. I wouldn't want my friends or family to know if I ever see a counselor.

8. I am aware of the counseling resources and location on this campus.

9. Financial limitations might prevent me from seeking counseling.

\section{Statement ratings• Means/ SD \\ American Chinese}

( $\mathrm{N}=148) \quad(\mathrm{N}=102)$

$1.78 / .65$

$1.79 / .73$

$2.17 / .84$

$3.54 / .60$

$1.59 / .65$

$2.47 / .64$

$2.78 / .68$

$2.84 / .91$

$2.51 / .84$

\subsection{4/.74}

$1.77 / .79$

$1.88 / .74$

$3.02 / .80$

$1.56 / .64$

2.26/.69

$2.59 / .80$

2.91/.95

$2.11 / .86$
T values

$-1.80$

$+0.19$

$+2.87 * *$

$+5.61 * *$

$+0.46$

+2.38 *

$+1.93$

$-0.61$

$+3.63 * *$

- strongly agree=1, Agree=2, Disagree=3, Strongly disagree=4 .

$* .01<\mathbf{p}<.05$

$* * \mathbf{p}<.01$. 


\section{Attitudes Toward Counseling and Services}

The data on Chinese and American students' attitudes toward counseling are summarized in Table 1. A two-way (nationality by sex) MANOVA on factors in attitudes toward counseling revealed significant differences by nationality on three factors: Factor I, $f(4,916)=4.580, p<.001$; Factor II, $f(4,916)=8.520$, $p<.001$; and Factor III, $f(I, 245)=6.902, p<.001$. Sex differences were significant on Factor $I, f(4,916)=$ $4.271, p<.002$. There was no two-way interaction for any of the three factors.

A follow-up analysis using ANOVA on each of the items yielded significant nationality differences for four items $(3,4,6$, and 9$)$, and sex differences for two items ( 7 and 8$)$. The four items numbered 3, 4, 6 , and 9 were further analyzed using a t-test. The results revealed that more Chinese students than American students agree with four statements: No. 3 "When I seek counseling, I prefer a direct, concrete answer to my concerns," $\mathrm{t}(248)=2.87, \mathrm{p}<.004$; No. 4 "I like the counselor to make decisions for me," $t(248)=5.90, p<.001$; No. 6 "When tests are utilized by a counselor, they are usually helpful," $t(233)=$ 2.41, p<.018; and No. 9 "Financial limitations might prevent me from seeking counseling," $t(244)=3.65$, $\mathrm{p}<.001$.

Two significant sex differences were found. More men than women tended to agree that they wouldn't want their friends or family to know if they ever saw a counselor, $t(246)=-2.69, p<.008$. More men than women also agreed that they were not aware of the counseling resources and locations on this campus, $\mathrm{t}(248)=3.31, \mathrm{p}<.002$.

\section{DISCUSSION AND IMPLICATIONS}

Preferences for Counselor's Characteristics

Chinese and American students have somewhat different preferences for a counselor's characteristics. More than half of the suggested characteristics (4 of 7 items) showed statistically significant differences between the two groups. Nevertheless, both groups agreed in general that these selected counselor characteristics were not of great concern to them. Counselors should note that Chinese students prefer counselors with the same racial background when they seek help for personal problems $(M=3.17, S D=1.79)$. The finding seems to be in accordance with other studies (Atkinson, Maruyama, \& Matsui, 1978; Bernstein et al., 1987; Sanchez \& King, 1986) in which Asian students described their counselors as more credible and competent if they are Asian-Americans. These findings seem to imply that counselors who are unable to relate to students on their cultural- racial background are perceived as much less effective in pro- viding help. American students, on the other hand, were less concerned about the counselor's racial background $(M=4.72, S D=1.58)$. The result is consistent with the result of Sattler's (1977) study that race is of less importance to White clients than it is to Black clients, perhaps because White clients are members of the majority group.

The finding suggested that Chinese students prefer an older counselor when they seek counseling for personal problems. A similar result was also found in Atkinson et al.'s (1984) study. The Chinese cultural tradition of respecting elder people for their wisdom and experiences may explain Chinese students' preferences for older counselors.

Chinese and Americans did not differ in their preferences for the sex of the counselor. Female students from both cultures, however, tended to prefer a female counselor rather than a male counselor to work with their personal problems.

\section{Image of a Counselor}

Chinese and American students have different images of a counselor. Among the six suggested counselor images, three of them were ranked differently by American and Chinese groups. Most American students perceived a counselor as a listener and friend. Most Chinese students, on the other hand, saw a counselor as a friend and expert. It is possible that the inclination to perceive the counselor as an expert rather than a listener may be because of the authoritarian orientation of Chinese culture (Tan, 1967). 
Yeun and Tinsley (1981), in a study of counseling expectancy, found that Chinese students expected more directiveness and more expertise from a counselor than did White American students. A person-centered, nondirective approach used by many American counselors may not be perceived as effective by Chinese students.

\section{Attitudes Toward Counseling and Counseling Services}

Attitudes toward counseling and counseling services are different between Chinese and American graduate students. Three attitudinal components-openness to counseling, expectation of the counseling process, and obstacles to counseling-were perceived differently by Chinese and American students.

It is worth noting that Chinese students have different ex-pectations of counseling than their American counterparts. Re-sults indicate that Chinese students are more likely to expect counselors to provide direct and immediate answers and to make decisions for them. These findings seem to parallel some other studies with Asian-Americans (see Leong, 1986) that have in-dicated that Asian students tend to view counseling as a direc-tive, paternalistic, and authoritarian process. Counselors should note that Chinese students come from a culture in which the family or the group is considered more important than the individual in decision making. American counseling strategies that emphasize the individual as central in all decision making may conflict with cultural values held by Chinese students. Differences in expectations between a counselor and Chinese students can create barriers to effective cross-cultural counseling. A great-er awareness of the Chinese students' counseling expectancies, and adopting an appropriate theoretical approach, may over-come this cultural barrier.

Although both Chinese and American students are generally open to seeking counseling, American students seem to be more ready to see a counselor. Both Chinese and American students, however, seem to lack knowledge about counseling and the counseling facilities available on American campuses. An effort to enhance the utilization of counseling services is especially important. Information about the purpose, facilities, personnel, and the actual counseling process should be included as part of the orientation for all incoming students. If students are better informed about the benefits of counseling, they may be more likely to use campus services. Counselors and student personnel workers should also be aware of the finding that financial lim-itations are likely to be an obstacle for Chinese students who are seeking counseling. A high counseling fee might prevent Chinese students from seeking counseling. A more flexible fee schedule seems preferable.

In summary, the differences between Chinese and American graduate students in their preferences for counselors characteristics, images of counselors, and attitudes toward counseling were compared and discussed. Counselors and student service workers need to be sensitive to these differences, as well as similarities, in planning and evaluating their counseling services for Chinese students. Counselors and student personnel work-ers, however, should not "pre-judge" on the basis of cultural diversity alone (e.g., racial-cultural background), but should rec-ognize that every individual is unique in his or her attributes (e.g., sex, age, personality, and socioeconomic background).

\section{REFERENCES}

Atkinson, D.R., Ponterotto, J.P., \& Sanchez, A.R. (1984). Attitudes of Vietnamese and Anglo-American students toward counseling. Journal of College Student Personnel, 25, 448-452.

Atkinson, D.R., Maruyama, M., \& Matsui, S. (1987). The effects of counselor race and counseling approach on Asian Americans' perceptions of counselor credibility and utility. Journal of Counseling Psychology, 25, 76-83.

Alexander, A.A., Workneh, F., Klein, M.H., \& Miller, M.H. (1976). Psychotherapy and foreign students. In P. Pederson, W.J. Lonner, \& J.G. Draguns (Eds.), Counseling across cultures. Honolulu: University Press of Hawaii, 82-97. 
Benedict, A.R., Apsler, R., \& Morrison, S. (1977). Student views of their counseling needs and counseling services. Journal of College Student Personnel, 18, 110-114.

Bernstein, B.L., Wade, P., \& Hofmann, 8. (1987). Students' race and preferences for counselor's race, sex, age, and experience. Journal of Multicultural Counseling and Development, 15, 60-70.

Cook, E.P., Park, W., Williams, G.T., Webb, M., Nicholson, B., Schneider, D., \& Bassman, S. (1984). Students' perceptions of personal problems, appropriate help sources, and general attitudes about counseling. Journal of College Student Personnel, 25, 139-145.

Dadfar, S., \& Friedlander, M.L. (1982). Differential attitudes of international students toward seeking professional psychological help. Journal of Counseling Psychology, 29, 335-338.

Dillard, J.M. (1983). Multicultural counseling: Toward ethnic and cultural relevance in human encounters. Chicago: Nelson-Hall.

Dillard, J.M., \& Chisolm, G.B. (1983). Counseling the international student in a multicultural context. Journal of College Student Personnel, 24, 101-105.

Fischer, E.H. \& Cohen, S.L. (1972). Demographic correlates of attitude toward seeking professional psychological help. Journal of Consulting and Clinical Psychology, 39, 70-74.

Harrison, D.K. (1975). Race as a counselor-client variable in counseling and psychotherapy: A review of the research. Counseling Psychologist, 26, 337-343.

Ho, M.K. (1973). Cross-cultural career counseling. Vocational Guidance Quarterly, 21, 186-190.

Institute of International Education. (1986). Open doors. New York: Author.

Lee, M. Y., Abd-Ella, M., \& Burke, L. (1981). Needs of foreign students from developing nations at U.S. colleges and universities. Washington, DC: National Association for Foreign Student Affairs.

Leong, F.T. (1986). Counseling and psychotherapy with Asian-Americans: Review of the literature. Journal of Counseling Psychology, 33, 196- 206.

Lum, R.G. (1982). Mental health attitudes and opinions of Chinese. In E.E. Jones \& S.J. Korehin (Eds.), Minority mental health (pp. 169-189). New York: Praeger.

Manese, J.E., Sedlacek, W.E., \& Leong, F.T. (1988). Needs and perception of female and male international undergraduate students. Journal of Multicultural Counseling and Development, 16, 24-29.

Proctor, E.K., \& Rosen, A. (1981). Expectations and preferences for counselor race and their relation to intermediate treatment outcomes. Journal of Counseling Psychology, 28, 40-46.

Sattler, J.M. (1977). The effects of therapist-client racial similarity. In A.S. Gurman \& A.M. Razin (Eds.), Effective psychotherapy: A handbook of research (pp. 252-290). New York: Pergamon.

Sanchez, A.R., \& King, M. (1986). Mexican Americans' use of counseling services: Cultural and institutional factor. Journal of College Student Personnel, 27, 344-349.

Smith, 0. (1974). Preferences of university students for counselors and counseling settings. Journal of College Student Personnel, 15, 53-57.

Sue, S., Wagner, N., Ja, D., Margullis, C., \& Lew, L. (1976). Conceptions of mental illness among Asian and Caucasian-American students. Psychological Report, 38, 703-708.

Snyder, J.F., Hill, C.E., \& Derksen, T.P. (1972). Why some students do not use university counseling facilities. Journal of Counseling Psychology, 19, 263-268.

Tan, H. (1967). Intercultural study of counseling expectancies. Journal of Counseling Psychology, 14, 122130.

Vontress, C.E. (1970). Counseling Blacks. Personnel and Guidance journal, 48, 713-719.

Yuen, K. W., \& Tinsley, H.E.A. (1981). International and American students' expectancies about counseling. Journal of Counseling Psychology, 28, 66-69. 